\title{
ОСНОВНЫЕ НАПРАВЛЕНИЯ СОВЕРШЕНСТВОВАНИЯ ОПЕРАТИВНОГО УПРАВЛЕНИЯ ПОСТАВКОЙ МАТЕРИАЛОВ
}

\section{(C) 2021 Дуболазов Виктор Андреевич}

доктор экономических наук, профессор Высшей школы производственного менеджмента Санкт-Петербургский политехнический университет Петра Великого, Россия, Санкт-Петербург

E-mail: Dubolazov-va@mail.ru

\section{(C) 2021 Симакова Зоя Леонидовна}

ст. преподаватель Высшей школы производственного менеджмента

Санкт-Петербургский политехнический университет Петра Великого, Россия, Санкт-Петербург

E-mail: simakova@kafedrapik.ru

Проблема оперативного управления поставкой материалов (ОУПМ) становится ключевой в закупочной логистике. Сформирована методика составления и корректировки календарных планов поставки материалов для разнотипного производства, учитывающая динамичность хода производства. Даны рекомендации по совершенствованию других стадий ОУПМ, сформулированы основные направления автоматизации и цифровизации ОУПМ.

Ключевые слова: закупочная логистика, поставка материалов, управление, автоматизация, цифровизация.

Первым этапом цепи поставки является поставка материалов, к которым также относятся готовые комплектующие изделия, покупные полуфабрикаты, услуги. Проблемы, ошибки и сбои, возникшие на этапе поставки материалов, приводят к возрастанию издержек и могут стать причиной проблем на следующих этапах цепи поставок.

Основные укрупненные этапы закупочной логистики: планирование потребности в материалах и количества материалов к заказу (нетто и брутто потребности); поиск, анализ и выбор поставщиков, проверка их благонадежности; переговоры и заключение договоров с поставщиками; оперативное управление поставкой материалов (ОУПМ) на предприятие.

В свою очередь ОУПМ, с кибернетической точки зрения на управление, заключается в оперативном планировании (составлении плановграфиков) поставки материалов на разные отрезки времени (от квартала - до реального времени), в оперативном учете, контроле, анализе и регулировании их выполнения с целью достижения цели ОУПМ - своевременного обеспечения предприятия материалами в требуемых номенклатуре, количестве и качестве при наилучших технико-экономических показателях и использовании ресурсов.

Основной функцией ОУПМ является оперативное планирование, которое делит- ся на оперативное объемное планирование и оперативно-календарное планирование поставки материалов.

1. Объемное оперативное планирование заключается в составлении оперативных планов поставки материалов. Для определения потребности в материалах учитывается план выпуска готовой продукции, потребность в запасных частях, необходимость для пополнения незавершенного производства. Объем закупок может быть не согласован с ресурсами других подразделений, например, склада или транспортного подразделения и не учитывает процесс поставки.

2. Оперативно-календарное планирование заключается в составлении календарных планов-графиков (КПГ) поставки материалов (составления заявки, погрузки, транспортировки, таможенного оформления и т.д.), загрузки ресурсов и реального календаря.

Оперативно-календарное планирование позволяет обеспечить равномерную работу и загрузку предприятия, транспорта, склада, спланировать размер страховых запасов. Задержка поставки и/или поставка в меньшем объеме, чем было запланировано, может привести к увеличению затрат, так как возникает потребность во внеплановом заказе или покупке у другого поставщика по более высокой цене. В случае поставки раньше времени и/или поставке из- 
лишних материалов возрастают затраты на хранение, «замораживание» оборотных средств в материальных запасах.

Оперативный учет поставки материалов играет важную роль в контроле и регулировании хода закупочной деятельности, является источником информации для оперативного экономического анализа, базой для составления плана закупок на последующие периоды времени и прогнозирования потребности в материалах, позволяет руководителям предприятия и связанных подразделений (складское хозяйство, транспортное) принимать своевременные решения, направленные на выполнение плановых поставок. Оперативный учет заключается в получении фактических данных об отгрузке материалов у поставщика, сроках, количестве и качестве (входной контроль) поставленных материалов, движении (приходе, расходе) материалов на складах и т.п.

К оперативному учету поставки материалов предъявляются следующие основные требования: своевременность, достоверность данных учета, сопоставимость учетных показателей с плановыми, наглядность, простота и немногочисленность сообщений с широким использованием технических средств сбора, передачи, обработки и выдачи информации.

Оперативный контроль производится за сроками и количеством запасов, сравнение фактических данных о количестве и сроках поставки с планируемыми или нормативными, контроль за уровнем запасов, комплектностью готовых комплектующих изделий (покупных полуфабрикатов), обеспеченностью производственного процесса необходимыми материалами, выявляются причины и величины отклонений.

Оперативный контроль поставки материалов осуществляется путем сравнения данных в информационной системе и фактического количества запасов, например, путем проведения полной внеплановой и плановой инвентаризации. Сравнение фактических данных о поставке по количеству проводится по транспортной накладной, из которой видно соответствие количества отгруженных и поступивших материалов. Однако эти данные не дают информации о количестве заказанных ТМЦ. Для материалов группы А и В (по совокупным затратам на закупку) рекомендована проверка сроков и объемов поставки с календарным планом-графиком. Периодичность проверок зависит от ритмичности поставок и сроков поставки, что является важным при длительных поставках из других стран или удаленных регионов России.

Для контроля хода поставок следует установить «контрольные точки». На машиностроительных предприятиях при контроле за поставками такими «точками» являются сроки отгрузки материалов у поставщика, прохождение таможенного оформления (при зарубежной поставке), поступление материалов на склад, а также размеры партий и соответствие поставки по качеству. Применение цифровых технологий, например, ІоТ позволяет вести такой контроль в режиме текущего времени. Это значительно упрощает процесс регулирования при возникновении отклонений.

По результатам оперативного контроля проводится анализ хода поставки материалов, который заключается в анализе отклонений, разработке мероприятий по устранениям причин отклонений при последующих поставках. Также анализируется отпуск материалов со склада на производство, фактический их расход. Отклонения в фактическом расходе могут быть связаны с низким качеством поставляемых материалов, а при использовании нескольких видов материалов возможно нарушение в пропорции применяемых материалов. Одной из рекомендаций по работе с отклонениями предлагается дополнительный входной контроль качества материалов при поступлении материалов в цех или на определенную операцию.

Регулирование состоит в устранении отклонений, их причин путем корректировки КПГ поставки материалов или составлении новых календарно-плановых графиков с учетом фактического хода поставки. Сегодня для участников цепи поставок очень важно оперативно и эффективно адаптироваться к изменяющимся условиям. Одним из часто встречающихся вариантов является постоянная корректировка спроса на производимую продукцию, что приводит к необходимости резкого изменения объемов поставки материалов (затруднение международных торговых отношений и работы транспорта, повышение затрат на логистику, непредсказуемость положения многих поставщиков и т.д.). В последние годы преобладающим критерием выбора поставщиков во всем мире является гибкость поставки. От поставщика требуется быстрое реагирование на возникающие новые потребности (изменения по объему по- 
ставки, срокам, виду используемого транспорта, маршруту доставки и др.). Таким образом, актуальность оперативного управления поставкой материалов только повышается и требует постоянного совершенствования.

Нами предлагаются следующие основные рекомендации по совершенствованию оперативного управления поставкой материалов:

- интеграция и синхронизация управления закупочной деятельности с управлением производством, продажами и другими стадиями цепи поставок [6];

- повышение оперативности учета, контроля, анализа и регулирования поставок материалов вплоть до реального времени;

- разработка динамичной системы оперативного управления поставкой материалов, учитывающей изменения внешних и внутренних факторов;

- разработка системы ответственности и мотивации поставщиков, а также подразделений и работников предприятия за своевременность поставки на основе системы сбалансированных показателей и КРI;

- автоматизация и цифровизация ОУПМ с широким применением IT-технологий, электронного документооборота, интернет вещей, киберфизических систем и других инструментов цифровизации;

- разработка цифровых двойников закупочной деятельности с использованием больших данных (Big Data), полученных из оперативного учета материалов, имитационного моделирования, нейронных сетей и других методов искусственного интеллекта.

Современное машиностроительное производство обладает следующими характеристиками:

- в зависимости от назначения производимая продукция может варьироваться от собственных нужд до потребностей рынка: от комплектующих до готовых изделий как давно выпускаемых, так и опытные образцы и изделия, изготовленные по новым технологиям;

- по особенностям производственного процесса - степени сложности организации производства, особенности технологического процесса, разной длительности производственного цикла (от нескольких дней до года);

- по характеру выпуска одновременно на предприятии могут выпускаться изделия единичного, серийного и массового производства.
Причем изменение спроса может приводить к увеличению или уменьшению объемов выпуска, то есть производство изделий одного и того же наименования может относиться к разным типам производства в разные периоды времени;

- одна из главных особенностей машиностроительного производства сегодня - высокая динамичность производства.

Таким образом, для обеспечения потребностей предприятий машиностроительной отрасли требуются разные материалы (по объему потребления, применяемости, место нахождения поставщика и т.д.), что влечет за собой применение разных методов при составлении календарного плана-графика: под заказ; на склад (с фиксированным ритмом поставки, фиксированным размером партии поставки, система «минимум - максимум»). В интегрированных системах управления 1C-Предприятие, SAP и других, получающих все большее распространение в РФ, применяются системы MRP, JIT, VMI, LP. B литературе [1,2], в том числе нами в [3], достаточно подробно изложены эти системы.

На решение проблемы направлена система MRP [4]. Концепция MRP - сроки поставки материалов определяются в соответствии с главным календарным планом производства (ГКПП) с учетом опережений запуска деталей (потребления материалов). ГКПП содержит план-график выпуска номенклатурных позиций продукции, выпускаемой предприятием, с указанием количества и сроков выпуска по дням (неделям, другим отрезкам времени с одинаковым ежедневным выпуском продукции). Составляется ГКПП на период, достаточный для заказа материалов, включающий длительность производственного цикла изготовления изделия, время на накапливание потребности в материалах по заказам до размера партии поставки и создание (пополнения) страхового запаса материалов.

При составлении ГКПП необходимо учитывать требования подразделений, от которых зависит выполнение плана. Отдел маркетинга и сбыта должен представлять информацию по потребителям по объему и срокам поставки; производственное подразделение заинтересовано в ритмичности производства и больших размерах производственных партий; отдел логистики заинтересован в закупке больших партий материалов и отгрузке готовой продукции большими объемами в одно место; финансовое подразделение должно планировать выполнение плана 
по выручке и прибыли путем ранней отгрузки продукции дальним потребителям.

В ГКПП вначале включаются изделия, принятые к изготовлению в соответствии с реальными, подтвержденными потребителями заказами. Затем включаются изделия заключенных договоров и, наконец, планируемые к выпуску в соответствии с прогнозом спроса. Заказы включаются в ГКПП до тех пор, пока хватает производственных ресурсов. При этом нами предлагается использовать методы оптимизации и системного анализа, например, метод морфологического ящика. Периодичность составления и корректировки ГКПП в зависимости от особенностей продукции и производства - месяц, декада, неделя. ГКПП часто меняется из-за появления неожиданных заказов от важных потребителей или отмены заказов покупателями. При всех достоинствах MRP ее недостатком остается недостаточная гибкости при оперативном изменении (динамичности) спроса на выпускаемую продукцию и самого производства, а также сложность реализации интегрированной системы управления.

Нами на основе работ Г. И. Коноваловой [5] по оперативному управлению динамичным разнотипным производством разработана методика составления КПГ и оперативного управления поставкой материалов для динамичного разнотипного производства, подробно изложенная в [6]. Сущность предлагаемой системы ОУПМ в том, что дата поставки очередной партии материалов определяется моментом, когда фактическое количество поставленных материалов с начала планируемого периода (года, квартала, месяца) сравняется с планируемом, равным

$$
\mathrm{M}_{p}=\sum_{k=1}^{K} M_{p k}
$$

где $k$ - порядковый номер рабочего дня с начала планового периода; $K$ - число рабочих дней с начала планового периода; $M p k-$ количество $p$-го типоразмера потребляемого в $k$-м рабочем дне, ед. изм., определяемое как

$$
M_{p k}=\sum_{k=1}^{K} N_{m k} * G_{p m}
$$

где $N m k$ - количество изделий $m$-го наименования, которое должно быть выпущено за $k$-й рабочий день, шт., Gpm - норма расхода материала $p$-го типоразмера на $m$-е изделие, ед. изм./шт.
В модели с фиксированной партией поставки срок поставки второй $Д_{2}$ и третьей $Д_{3}$ и последующих партий материалов определяется по формуле

$$
\begin{aligned}
& n_{2}=\sum_{k=д_{1}}^{Д_{2}} M_{k}=n ; \\
& n_{3}=\sum_{k=д_{2}}^{Д_{3}} M_{k}=n \text { и т.Д., }
\end{aligned}
$$

где $Д_{1}-$ срок поставки первой партии материалов в планируемом месяце, раб.дн.; $n-$ нормативный (фиксированный) размер партии поставки материалов, ед. изм.

С учетом партионности поставки материалов уточняется количество материалов, которое надо поставить за месяц, как

$$
\mathrm{M}_{\text {мес }}=K_{n} * n,
$$

где $\mathrm{Kn}$ - количество партий материалов, которое должно быть поставлено за месяц.

В модели с фиксированным ритмом поставки материалов сроки поставки второй $Д_{2}$, третьей Дз и последующих партий материалов планируются через ритм, то есть $Д_{2}=Д_{1}+R ; Д_{3}=Д_{2}+R$ и т.д. до конца горизонта планирования, где $R-$ фиксированный (нормативный) ритм поставки партий материалов, раб. дн. Размеры второй $n_{2}$, третьей $n_{3}$ и последующих партий материалов, которые при этом не равны фиксированному (нормативному) размеру, определяются как

$$
\begin{aligned}
n_{2} & =\sum_{k=A_{1}}^{R} M_{k} ; \\
n_{3} & =\sum_{k=д_{2}}^{R} M_{k} \text { и т.д. }
\end{aligned}
$$

Дата отправки заявки на поставку этой партии материалов должна ранее дня поставки на длительность поставки в зависимости от поставщика: его места нахождения, длительности изготовления и подготовки заказа к отправке, способа и времени доставки, таможенного оформления и т.д.

Автоматизация и цифровизация становятся одним из приоритетных направлений инновационного развития логистики. Цифровизация общества, четвертая промышленная революция, Логистика 4.0 базируются на применении цифровых технологий, основанных на использовании Интернет, облачных и квантовых технологий, интернета вещей, робототехники, ки- 
берфизических систем, технологии 5G, Big Data, нейронных сетей, 3D-печати, искусственного интеллекта и машинного обучения, технологии виртуальной и дополненной реальности и других [7].

Применение в управлении предприятиями ЭВМ, интернет, других средств цифровизации способствует централизации управления предприятиями и их комплексами (холдингами, концернами и др.), оказывают существенную помощь при консолидации закупок в интересах нескольких заказчиков одновременно, поиске информации о рынке материалов и поставщиках, переговорах с поставщиками, оперативном управлении поставкой материалов [8]. Централизация и консолидация закупочной деятельности с помощью средств цифровизации также исключает дублирование заявок на материалы, способствует своевременности оплаты поставок, оптимизирует платежи в зависимости от приоритетности поставщиков, повышает профессионализм и единый подход при работе с поставщиками, сокращает внешние расходы, улучшает другие направления совершенствования закупочной деятельности.

В настоящее время наибольшее распространение получила цифровая трансформация процессов проведения закупочной процедуры и выбора контрагентов с использованием электронных торговых площадок (ЭТП), маркетплейсов, агрегаторов. В перспективе важно, чтобы эти площадки не только выбирали поставщиков, но и стали бы инструментом по их развитию, проверке благонадежности и оценке, подбору оптимальных поставщиков, по автоматизированному проведению закупок материалов без документов в режиме реального времени на основе технологий искусственного интеллекта. В перспективе прогнозируется создание межотраслевых информационных и даже глобальных экосистем для поиска и отбора поставщиков. Перспективно создание системы предиктивной аналитики, основанной на анализе big data, для планирования непрогнозируемых потребностей материалов [9].

Определенный прогресс в настоящее время достигнут в цифровой трансформации процессов подготовки закупочной документации, электронного документооборота (ЭДО) и мониторинга закупочной деятельности. ЭДО предполагает практически моментальный обмен документами с контрагентами, государственными органами, что способствует сокращению сроков согласования, подписания и возвращения документов, повышению оперативности принятия решений. Особенно это важно при организации международного обмена документами. ЭДо уменьшает риск утраты документов, упрощает их хранение, сокращает время и денежные средства, затрачиваемые на доставку и обработку документов. Растет корпоративная культура на предприятии. Руководителям легче контролировать движение документа, в реальном времени узнать, кто над ним работает в данный момент. При ЭДО повышается контроль за количеством продукции, появлением контрафактной продукции. Тесная взаимосвязь между материальным, информационным и финансовым потоками залог эффективности управления логистическими процессами.

Перспективным направлением цифровизации логистики является применение Интернета вещей (IоT). Современные инструменты и приборы измерений (датчики, контроллеры, видеокамеры и т.п., в том числе оснащённые алгоритмами машинного зрения/обучения) позволяют отслеживать перемещение и хранение материалов на складе, работу транспорта и поставку материалов, использование оборудования (сроки его замены и ремонта, поставки запасных частей и т.п.) и изготовления продукции. В комплексе с информационными системами и вычислительными ресурсами ІоТ формирует цифровую логистическую систему предприятия, киберфизические системы управления производственными комплексами. Развитие логистической системы при этом идет по пути управления движением материалов по всей цепи поставок в режиме реального времени, что позволит оперативно реагировать на любые изменения и обеспечит всех участников цепи поставок точной информацией, данными для big data.

Развитие технологии 3D-печати в логистике способствует росту возможностей для кастомизации заказов - выпуску продукции по индивидуальным заказам потребителей (например, вследствие внесения конструктивных или дизайнерских изменений), требующей новых материалов (комплектующих изделий) в небольшом количестве. Немного материалов требуется также для научно-исследовательских работ, технологических испытаний, ремонтных работ и т.п. Применение технологии 3D-печати позволит обеспечить их своевременную поставку. 
Выводы и дискуссия. Закупки превратятся из центра затрат в центр прибыли. Это становится возможным по причине быстрого развития интернета вещей и искусственного интеллекта.

Цифровизация касается логистических процессов как внутри предприятия, так и всей цепи поставок, поэтому необходимо их комплексное совершенствование, а также изменения в глобальной логистике. В этих условиях меняются логистические бизнес-процессы, инфраструктура логистики, в том числе закупочной, функции подразделений и работников, методы оценки и мотивации их деятельности.

Цифровое производство - это не только внедрение новых технологий, но и глубокое преобразование стратегии развития предприятий, организационной корпоративной структуры и управления, работы с контрагентами [3]. Требуется разработка новых методов формирования архитектуры предприятий, методов и моделей управления предприятием и его подразделениями [4].

\section{Библиографический список}

1. Сергеев В. И. Логистика снабжения: учебник для вузов / В.И. Сергеев, И. П. Эльяшевич. - М.: Изд-во Юрайт, 2020. $-440 \mathrm{c}$.

2. Щербаков В.В. Логистика и управление цепями поставок: учебник для академического бакалавриата/ В. В.Щербаков [и др.]; под редакцией В. В.Щербакова. - Москва: Издательство Юрайт, 2019. - 582 с.

3. Дуболазов В.А., Симакова З.Л. и др. Онлайн курс Логистика URL: https://openedu.ru/course/spbstu/LOGIST/

4. Гаврилов Д. А. Управление производством на базе MRP II. 2-е изд. - СПб. Питер, 2005.

5. Коновалова Г.И., Концепция оперативного управления динамичным разнотипным машиностроительным производством // Менеджмент в России и за рубежом. - 2018. - № 2. - С. 27-34.

6. Дуболазов В.А., Симакова З. Л. Оперативное управление поставкой материалов при динамичной интенсивности их потребления//Логистика, 2017, № 8. С.2-5

7. Schwab K. The Fourth Industrial Revolution. Hardcover BUY. Jan. 03, 2017. 192 p.

8. Dubolazov V., Simakova Z., Leicht O., Shchelkonogov A. The Impact of Digitalization on a Production Structures and Management in Industrial Enterprises and Complexes//Scientific International Conference «Technological transformation: a new role for human, machines and management (TT-2020)» ISSN 2367-3370

9. Цифровая трансформация корпоративных закупок: достижения, потенциал, проблемы//RAEX, 8.04.2021 